\title{
RESENHA DAS OBRAS
}

Memórias de

um professor

de antigamente

OHando Roberto do Nucimento
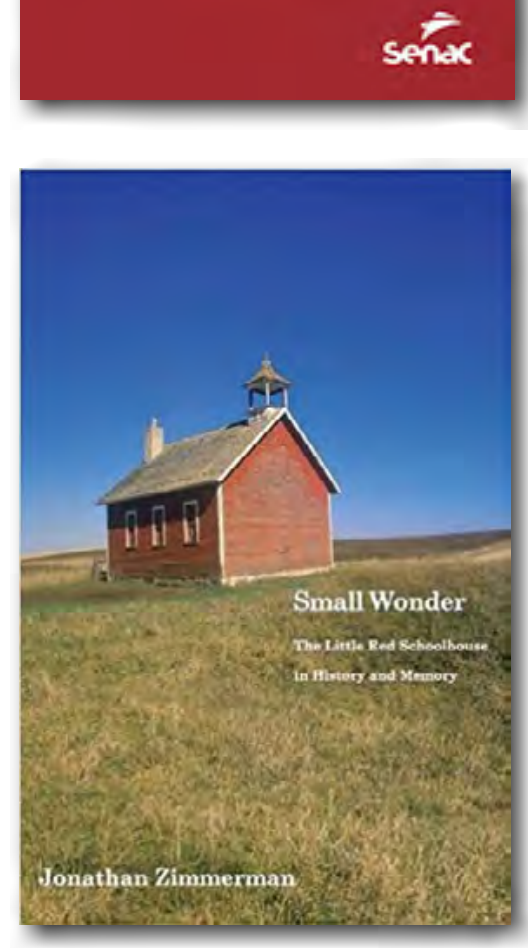

NASCIMENTO, Orlando Roberto. Memórias de um professor de antigamente. São Paulo: Editora Senac São Paulo, 2020.

\section{Escola de roça: limites e inspirações}

A escola de hoje é um dos produtos da urbanização. Com o crescimento das cidades, as instituições educacionais se organizaram em estabelecimentos complexos, com muitas salas de aula e diversos ambientes de apoio, como quadras de esportes, laboratórios, bibliotecas, cantinas etc. Além disso, nas escolas urbanas há diversos professores, diretores, coordenadores, psicólogos, bibliotecários, secretários escolares, cozinheiras, auxiliares de secretaria e demais profissionais. Elas são inteiramente diferentes das escolas rurais de sala única, regidas por um só professor. As condições de funcionamento das escolas de roça, se comparadas com as escolas atuais, sugerem muitos limites. Ao mesmo tempo, sugerem abordagens metodológicas que ganharam espaço em propostas pedagógicas avançadas. 
As escolas de roça costumam ser objeto de admiração. Elas nos desafiam a entender como lá se desenvolvia a aprendizagem. Alguns dos movimentos educacionais mais respeitados do século XX têm semelhanças com o que acontecia nas escolas rurais. Um deles é a Escola de Barbiana, o revolucionário projeto educacional conduzido por Don Milani (BATINI; MAYO; SURIAN, 2014). Em Barbiana, como nas escolas de roça, alunos de todas as idades aprendiam no mesmo espaço. Além disso, alunos mais avançados ajudavam estudantes dos níveis anteriores ou que tinham dificuldade para aprender. Em Barbiana, assim como na escola de roça, havia apenas um professor para todos os alunos. E, embora Milani não tenha elaborado suas propostas com base em conhecimentos sobre a pedagogia de projetos, em sua escola alunos de diferentes níveis e idades trabalhavam juntos para estudar temas de interesse comum. De certa forma isso também acontecia nas antigas escolas rurais.

Na minha adolescência desenvolvi grande admiração pelas escolas de roça. O motivo era um livro de geografia, utilizado na escola de roça onde meu pai estudou. Desde pequeno, eu lia e relia aquele livro. A obra tinha conteúdos que só fui estudar no terceiro ano de ginásio (atual sétima série). Vale lembrar que os alunos permaneciam nas escolas rurais apenas três anos. Ou seja, meu pai utilizou aquele livro de geografia em um período que as escolas da cidade classificariam como terceiro ano primário, quatro anos antes da sétima série. Aquele livro era motivo de conversas com meu pai sobre a escola que ele frequentou na zona rural. Eu soube que ele ensinava alunos dos níveis menos avançados. Soube que, com apenas doze anos de idade, ele substituía a professora caso ela se ausentasse. E mais, foi na escola de roça que meu pai desenvolveu conhecimentos de controle contábil, que veio a utilizar, nos tempos em que foi meeiro em fazendas de café, para acertar as contas com seus parceiros. Nas conversas com ele construí uma imagem muito otimista e romântica da escola de roça.

Minha curiosidade sobre as escolas rurais, a partir de narrativas sobre a educação que meu pai recebeu, continuou pela vida afora. Mas nunca estudei academicamente como acontecia a educação nas escolas rurais. Nas faculdades de Educação, que frequentei como aluno e como professor, as escolas rurais não eram objeto de estudo. Sempre vi nisso uma falha na formação de professores. No meu entender, estudos sobre as escolas de roça poderiam enriquecer não só nossos conhecimentos sobre história da educação, mas também fornecer indicações interessantes sobre processos de aprendizagem.

Orlando Roberto do Nascimento, velho companheiro de trabalho no Senac de São Paulo, foi professor de escola de roça. Depois de concluir o Curso Normal, assumiu uma escola no Vale do Ribeira. Jovem professor de curso primário, sem qualquer experiência docente, Orlando teve que inventar ou aprender com professores rurais experientes novos caminhos de ensino, pois não aprendera em sua formação como ser docente em uma sala única, com alunos de diferentes idades e níveis de conhecimento. Por essa razão, eu o convidei para escrever um microlivro digital sobre as aventuras de professor na roça para uma coleção de obras editadas por Car- 
los Seabra. A coleção sofreu descontinuidade antes que a obra do Orlando estivesse pronta para publicação. No entanto, felizmente, a Editora Senac se interessou por ela. O texto recebeu o necessário tratamento para se converter em livro editado em papel. E, assim, passamos a contar com um registro de experiência que atenua a ausência de literatura sobre a educação em escolas rurais no Brasil. Orlando escolheu escrever suas memórias dos tempos de professor de roça em crônicas deliciosas. Em seu escrito ele dá vida para uma escola à beira do rio Ribeira, no meio dos bananais. 0 prédio escolar, o dia a dia do professor, o comportamento dos alunos, a participação da comunidade no trabalho educacional são alguns dos aspectos que aparecem no livro.

Nos Estados Unidos, estudos e publicações sobre escolas rurais são numerosos. Além disso, nas artes, há muitas obras voltadas para a Little Red Schoolhouse, rótulo que designa as escolas rurais americanas, apesar de a maioria delas não ser vermelha. O rótulo, porém, criou uma marca que passou a dominar o imaginário das pessoas quando falam sobre escolas rurais, qualquer que seja a cor de suas paredes.

The Little Red Schoolhouse é um fenômeno que merece análise tanto do ponto de vista histórico quanto do ponto de vista dos mecanismos culturais, sociais e psicológicos que deram origem a uma projeção da escola rural como um paraíso perdido que precisa ser recuperado ou, pelo menos, pode servir de inspiração para a educação atual. Jonathan Zimmerman (2009) faz essa dupla análise, registrando dados e fatos de caráter histórico, e examinando as imaginosas construções sociais que colocaram a Little Red Schoolhouse no panteão dos símbolos nacionais americanos.

Como há uma riqueza de dados e registros históricos sobre as escolas de sala única nos Estados Unidos, julguei que seria interessante apresentar uma análise da obra de Zimmerman antes de resenhar o livro de Orlando Roberto do Nascimento. Isso pode oferecer um contraponto para as histórias que Orlando conta e, ao mesmo tempo, indicar direções para futuros estudos acadêmicos sobre nossas escolas rurais.

\section{The Little Schoolhouse}

O título do livro de Jonathan Zimmerman é Small Wonder: The Little Red Schoolhouse in History and Memory (ZIMMERMAN, 2009). A pequena maravilha, lembrada com muito carinho pelos americanos, é um produto da memória coletiva. Muitos autores de músicas, poemas e romances sobre a Little Red Schoolhouse não a frequentaram. Exemplo disso é a música Schooldays, composta no começo do século passado. O compositor, Gus Edwards, era um imigrante alemão, educado em Nova Iorque e possivelmente nunca entrou em uma escola rural. No entanto ele conseguiu captar artisticamente o sentimento predominante quanto às escolas rurais que existiram por toda parte nos Estados Unidos. Schooldays é considerada uma das dez mais importantes canções americanas do século XX. Mais de 3 milhões de cópias de sua partitura foram vendidas no país, e ela integrou diversos musicais que foram produzidos sobre as escolas do campo. Sugiro ao leitor ida ao YouTube para ouvir uma das versões de Schooldays. 
Outra referência de registro de sentimentos sobre a escola rural nos Estados Unidos aparece na pintura. A obra marcante nesse sentido é Snap the Whip, de Winslow Homer, mostrando um grupo de rapazes que brinca alegremente em um relvado que tem ao fundo uma escola de paredes vermelhas. Essa pintura de Homer, reproduzida em branco e preto nos meios de comunicação da época - segunda metade do século XIX - acabou consolidando a ideia de que as pequenas escolas do meio rural do país tinham as paredes tingidas de vermelho.

Há muitas outras produções que têm a Little Red Schoolhouse como tema. São romances, peças de teatro, musicais, ensaios publicados na imprensa. Quase todas elas passam a ideia de um tempo feliz vivido nas acanhadas instalações das escolas de sala única. A visão cor-de-rosa sobre a escola rural do país é hegemônica. Ela existe, pelo menos, desde a metade do século XIX. Mas sofreu críticas em duas épocas distintas.

No final do século XIX, muitos defensores da Escola Nova se opuseram a ideias otimistas quanto ao ensino que se praticava nas escolas do campo. Segundo a maioria dos escolanovistas, a Little Red Schoolhouse promovia uma educação baseada em memorização e praticava uma disciplina rígida, recorrendo muitas vezes à violência física. Mais tarde, durante a Grande Depressão, apareceram críticos que caracterizavam as escolas rurais como instituições precárias. Fotógrafos percorreram o país fazendo imagens de escolas malconservadas, sem recursos, decrépitas. No primeiro caso, as críticas surgiram em uma situação na qual a urbanização crescia de maneira acelerada. No segundo caso, as críticas se referiam ao descaso com a educação, vendo nos limitados investimentos em escolas rurais sinal de que o país não buscava resolver problemas graves da pobreza.

A visão romântica da Little Red Schoolhouse e o papel de símbolo nacional de tal instituição sempre foram utilizados com finalidades políticas. Zimmerman dá diversos exemplos nessa direção. Destaco dois. O primeiro foi a utilização do citado símbolo para promover o programa No Child Left Behind, projeto desenvolvido com o objetivo de garantir educação de qualidade para todas as crianças. No lançamento do programa, em todas as entradas do edifício central do Ministério da Educação, foram construídas imitações de uma Little Red Schoolhouse típica, com seu telhado de duas águas e uma pequena torre. No pórtico dessas imitações, em vez do nome Little Schoolhouse, apareciam os dizeres No Child Left Behind. Dessa forma, associava-se o sentimento de um passado róseo em educação com um projeto que pretendia recuperar os melhores rumos escolares a partir de 2002. O segundo exemplo é uma propaganda divulgada por candidato ao Conselho de Educação de uma pequena cidade americana. Tratava-se de um vídeo em que o candidato, Chistopher Knight, aparece como herói, brandindo um sabre de luz, como o utilizado por Luke Skywalkwer em Guerra nas Estrelas, para defender a Little Schoolhouse contra as forças do mal. Knight utilizou a imagem da antiga escola rural para acentuar suas propostas de defesa de uma educação governada pela comunidade local, livre da burocracia centralizadora do estado. Essa é uma das ideias continuamente 
associadas às antigas escolas rurais e tem certa base histórica, pois as instituições escolares das áreas para as quais migravam os pioneiros eram inteiramente governadas pela comunidade local.

As direções de como se projeta a figura da Little Red Schoolhouse podem diferir entre esquerda e direita. Educadores identificados com ideias liberais (de esquerda) veem nas escolas rurais exemplos de uma educação que realça a cooperação, o trabalho em grupo. Esses mesmos educadores, em diferentes épocas, viram na escola rural americana um exemplo de sala de aula aberta e de educação que não separa os alunos rigidamente em faixas etárias e níveis de aprendizagem. Já educadores identificados com ideias conservadoras (de direita) veem na Little Red Schoolhouse um exemplo a seguir em termos de disciplina e de ensino voltado para conteúdos. Ambos os lados constroem narrativas sobre as escolas rurais para favorecer seus pontos de vista. E há elementos na história das escolas do campo da nação americana para apoiar um ou outro lado.

O sentimento que converteu a Little Red Schoolhouse em símbolo nacional conheceu diversas fases. Para Zimmerman, ele existe desde a metade do século XIX. Sofreu críticas por volta da década de 1890 e durante a Grande Depressão (anos em torno de 1930). Mas, a partir da II Guerra, a ideia de que a escola rural americana é um exemplo de educação que promove tanto a iniciativa individual como práticas de vida comunitária, trabalho duro para aprender e cooperação entre os alunos, de tal modo que a educação democrática converte-se em pensamento hegemônico, com reflexos na academia, nas artes e nos meios de comunicação.

Zimmerman analisa acontecimentos que mostram o sentimento nacional inteiramente favorável à Little Red Schoolhouse. Destaco aqui um dos registros feitos por ele. Personagens importantes da política, das artes e dos negócios promoveram iniciativas para que a tradição das escolas rurais fosse conservada. Um desses personagens foi Henry Ford. O magnata da indústria automobilística foi aluno de uma Little Red Schoolhouse, frequentada não só por ele, mas também por cerca de 30 pessoas da família, inclusive sua mãe. Ford se lembrava com carinho dessa escola. Transferiu-a, tijolo por tijolo, para um parque-museu. E pagou a alunos do ensino fundamental para que se inscrevessem na escola que ele recuperou. No entanto o ensino que se fazia nessa escola arquitetonicamente recuperada pouco tinha a ver com o oferecido nos tempos em que Ford lá estudou. A recuperação física do prédio escolar não foi acompanhada por um revival da educação típica de uma Little Red Schoolhouse. Ao relatar o esforço de Ford para recuperar sua antiga escola, Zimmerman nota que a iniciativa do magnata tinha um quê de ironia. Automóveis e ônibus, somados à melhoria das estradas exigidas por esses novos meios de transporte, favoreceram o desenvolvimento das grandes instituições escolares que, graças às facilidades de deslocamento dos alunos, faziam com que a pequena escola rural, que costumava estar próxima da residência dos estudantes, deixasse de ser vantajosa. Ford promovia a recuperação de velhas escolas rurais, mas ao mesmo tempo e indiretamente, contribuía para seu declínio. 
Passo agora a apontar alguns dos elementos factuais que o autor apresenta sobre as escolas de sala única nos Estados Unidos. Nos tempos em que poucas cidades do país tinham mais que 2.500 habitantes, a população era muito dispersa e vivia em vilas ou comunidades rurais. Nessas localidades, havia uma escola. No século XVIII e começo do século XIX, predominavam construções feitas de troncos. Com o tempo, essas estruturas rústicas deram lugar a edificações cujas paredes eram feitas com painéis de madeira. $O$ livro de Zimmerman tem algumas ilustrações com imagens de escolas de sala única, mas não inclui fotos ou pinturas de escolas feitas de troncos (log cabins), nem de escolas cujas paredes sejam de painéis de madeira. A partir das indicações da obra sobre os edifícios das escolas de sala única, fiz um levantamento de imagens existentes na internet. Selecionei tais imagens e, para os interessados, publiquei a resultado em um dos meus blogs (BOTECO ESCOLA, 2020). O autor observa que as iniciativas das comunidades de pioneiros americanos, estabelecendo escolas em seu território, converteram o país na nação com maior índice de escolarização nos séculos XVIII e XIX.

A escola de sala única, no geral, era precária. Por toda parte, sua planta era muito parecida. Um prédio pequeno, com telhado de duas águas e torre, tinha cerca de 15 metros de comprimento por sete de largura. De cada lado da construção havia três janelas. Na parte central da escola, havia um fogão para calefação. Os alunos se acomodavam em bancos sem encostos, voltados para mesas junto às paredes. Não havia quadro negro, mapas, cartazes ou qualquer outro recurso de apoio para o professor. Também não havia banheiros. Em algumas escolas, para suas necessidades físicas, os alunos deviam procurar locais isolados nas cercanias. Em outras escolas havia sanitários com fosso, um para os meninos, outro para as meninas.

Zimmerman faz diversas observações sobre os professores. Eles não tinham formação para o magistério e poucos deles tinham escolaridade correspondente ao segundo grau. Os contratos de trabalho eram feitos entre o professor e a comunidade que mantinha a escola. Quase sempre, contratava-se uma professora para os meses de verão e um professor para os meses de inverno. Essa prática tinha a ver com disciplina. No verão, devido às demandas de trabalho no campo, alunos mais velhos não frequentavam as aulas. Por essa razão, nessa estação havia menos problemas disciplinares. Já no inverno, com alunos de mais idade no recinto escolar, era preciso um docente - quase sempre homem - que pudesse manter a disciplina com certo rigor. Os docentes eram muito jovens. As mulheres eram quase sempre moças com idade girando em torno dos 17 anos. Os homens talvez fossem um pouco mais velhos, pois muitos deles assumiam docência em escolas rurais assim que concluíam um curso superior. Durante muito tempo - até finais do século XIX - não se contratavam professoras casadas. Homens que ingressavam no magistério tinham na docência uma ocupação de passagem; permaneciam nas escolas apenas por um ou dois períodos. Finalmente, registro uma curiosidade que aparece no livro de Zimmerman: oito presidentes americanos foram, no início de suas carreiras, professores de escolas rurais. 
Docentes de escolas rurais eram muito mal remunerados. Ganhavam 1/3 do que auferiam professores em escolas urbanas. O contrato de trabalho era bastante precário e feito para períodos curtos. O ensino era conteudista. Os alunos deviam decorar fatos, tabuadas, e recitar de cor trechos de livros. Dificilmente se encontrava material didático para auxiliar o processo de alfabetização e leitura. Alunos que possuíam algum livro em casa levavam-no para a escola e o professor incentivava o estudante a ler e recitar a obra. Tarefas de trabalho e estudo eram atribuídas aos alunos pelo nível de avanço em que se encontravam. E uma das condições mais solicitadas pelos docentes era a de que os alunos estudassem mantendo silêncio. Nas palavras de Zimmerman (2009, p. 173):

Cuidando de muitos alunos de diferentes idades e capacidades, muitos professores tentavam implantar silêncio acima de tudo; 'na verdade', um professor do século XIX escreveu, 'uma sala de aula silenciosa era considerada o ápice da excelência pedagógica'.

Na obra de Zimmerman fica claro que a docência em escolas de sala de aula única era uma atividade baseada em senso comum. Os docentes não tinham qualquer preparação prévia para ensinar. Poucos eram os recursos disponíveis. Mas há um aspecto que o autor não examina devidamente. Durante cerca de dois séculos quase toda a educação fundamental no país acontecia em escolas rurais. Apesar de muitas limitações, os alunos desenvolviam conhecimentos básicos de leitura, escrita e cálculo. Muitos intelectuais e políticos do país, entre os quais vários presidentes da república, educaram-se na Little Red Schoolhouse. O autor opina que essas personalidades todas tiveram sucesso, apesar da escola fundamental que frequentaram. Essa é uma opinião discutível. No fim do século XIX, havia no país um quarto de milhão de escolas rurais. Nelas se formava a maior parte da população. E os resultados não eram desprezíveis. O país, como já se observou, universalizou dessa maneira o ensino fundamental muito antes que outros países o fizessem. E, no interior das salas de aula, professores muito jovens tinham que inventar caminhos que Ihes possibilitassem ensinar simultaneamente a alunos de idades e capacidades diferentes. Essa experiência pode iluminar alguns caminhos da educação. Escolas gigantescas, com divisões rígidas dos níveis de escolaridade, estão fazendo uma educação despersonalizada, desvinculada dos interesses das comunidades que as cercam. Talvez escolas menores, nas quais alunos de diferentes idades possam aprender juntos, sejam um caminho que traga melhorias significativas para a educação. Nesse sentido a Little Red Schoolhouse pode ser um farol interessante para novas navegações educacionais.

\section{Escola em uma curva do rio Ribeira}

Ano de 1964. Na cidade de Registro, o jovem professor embarca em lancha que o levará ao porto de uma das curvas do rio Ribeira. Lá ele vai encontrar a escola onde deverá ensinar. É um prédio acanhado, à beira do rio, perdido na imensidão dos bananais. Há uma sala de aula única, uma pequena sala de apoio, uma cozinha e um 
minúsculo dormitório. Não há luz elétrica, nem água corrente. Perto da casa há dois banheiros com fossas. No local, ele será docente e gestor escolar. Não há qualquer pessoal de apoio. E no dia em que o jovem professor chega, não há ninguém para recepcioná-lo, a não ser um dos alunos, que lhe entrega a chave da escola. Essa situação impactante é descrita por Orlando Roberto do Nascimento em Memórias de um Professor de Antigamente (NASCIMENTO, 2020). Ele é o jovem professor que vai começar a carreira docente em uma escola de roça do Ribeira.

Orlando formou-se em um ótimo Curso Normal do Instituto de Educação Otoniel Mota, de Ribeirão Preto, São Paulo. O curso, porém, não o preparou para o impacto de assumir a docência em uma distante escola perdida no meio de bananais. Ainda assim, ele não desconhece escolas de roça. A primeira que conheceu foi organizada na sala de estar da casa de seus pais em um sítio de Pedregulho, SP. Nessa escola, ele participava das aulas conduzidas por uma de suas irmãs, professora primária sem formação docente. Mais tarde, Orlando continuou estudos em outra escola de roça e concluiu seu curso primário em uma escola urbana. Assim, embora o Curso Normal não o tivesse preparado para docência em uma escola rural, ele tinha experiência pessoal de como acontecia a educação nas escolas de roça.

Nas narrativas do autor de Memórias de um Professor de Antigamente destacam-se diversas observações sobre envolvimento da comunidade com a educação. Uma família japonesa cuja casa era a moradia mais próxima da escola - a uns vinte minutos de caminhada - oferecia refeições para o professor. A mesma família se articulava com o inspetor de ensino da região para avaliar o desempenho do professor, assim como solicitava novo professor em caso de vacância docente. Outra família japonesa da região, cujo filho era companheiro de Orlando no time de futebol, apoiava o professor. Uma das moças da família se propõe a ir à escola para ensinar música para as crianças. Outros contatos com sitiantes e trabalhadores da região sugerem interesse da comunidade pelo que se faz na escola. Observações do autor sobre essas articulações entre comunidade e escola lembram o que acontecia em uma escola rural em Montana, USA, nos anos de 1990 (ROSE, 1995). Mike Rose selecionou, no estado de Montana, onde ainda existem instituições rurais de ensino, uma escola, para acompanhar atividades educacionais na comunidade de Polaris. Lá a escola de roça continuava a existir, com uma sala de aula única, abrigando alunos de diferentes níveis e idades. Um professor, com diversas experiências prévias em projetos sociais, assumiu as aulas na escola. O que ele fazia sempre era negociado com o conselho escolar local. E atividades em áreas que ele não dominava eram desenvolvidas por voluntários capazes encantar os alunos com projetos interessantes. Rose, nas semanas em que esteve observando aquela escola de roça, presenciou o trabalho voluntário de uma artista plástica que veio à escola para ensinar técnicas que dominava para os alunos.

No Vale do Ribeira e em Montana, pequenas escolas, regidas por um só professor, experimentavam uma articulação entre comunidade e instituição educacional que inexiste nas escolas urbanas. Em ambos os casos havia grande proximidade 
entre o professor e a comunidade local. Zimmerman observa que a escola rural é lembrada por educadores que propõem que as unidades escolares sejam pequenas. Experiências das escolas de sala única dão razão a esses educadores quando eles sugerem que um número reduzido de alunos em unidades escolares facilita articulações com o entorno. As histórias contadas por Orlando comprovam isso. 0 professor frequenta a casa das famílias de seus alunos e recebe ajuda da comunidade para complementar as atividades de ensino. Assim ele aprende muito com os alunos e com a comunidade.

Em escolas do Vale do Ribeira, era comum a oferta de cursos de alfabetização de adultos. Na escola em que atuava, Orlando conduziu um desses programas, utilizando o método de Paulo Freire, aprendido em sua militância na Ação Católica. Os alunos eram trabalhadores dos bananais. Muitos deles tinham seus filhos ali matriculados no Ensino Fundamental. Esse é mais um fato que reforçava a articulação entre escola e comunidade.

Alunos de diferentes idades e níveis de conhecimento, ocupando o mesmo espaço e contando com um único professor, podem provocar grandes problemas disciplinares. Esse aspecto é destacado na obra de Zimmerman. Mas no caso da escola do Vale do Ribeira não havia indisciplina. Orlando escreve que os alunos, filhos de sitiantes japoneses e de trabalhadores nordestinos, eram muito educados. Isso parece sinalizar que a comunidade local valorizava a escola. Como a obra se refere apenas a uma unidade escolar, não há condições de saber se essa maneira respeitosa de ver a escola acontecia em todas as comunidades rurais.

O autor confessa que não tinha muita segurança de como iria conduzir o trabalho docente. No Curso Normal se preparara para ensinar em classes seriadas e, no Vale do Ribeira, precisava atender alunos de diversos níveis em uma mesma sala. Para sua sorte, os alunos o ajudaram. Os estudantes chegaram de diversas partes dos bananais e ficaram aguardando chamado para entrar na escola, ou, como narra o autor, instrução para organizar uma fila e cantar o hino nacional antes do começo das atividades. São os alunos que dizem ao novo professor que essas medidas preliminares deveriam ser tomadas antes do ingresso na sala de aula. Os alunos finalmente entram, e o autor (NASCIMENTO, 2020, p. 39-40) assim descreve o acontecido:

Mais uma vez, por ordem não sei de quem, os nove do primeiro ano ocuparam a fila de carteiras - dois em cada uma - mais próxima à porta da escola; na fileira do meio, ficaram os do segundo ano e, junto à janela que dava para o bananal, à esquerda, numa carteira sentaram-se Mário e Zencho [alunos do terceiro ano].

Mário e Zencho, mesmo sem serem solicitados, tomam iniciativas para facilitar o trabalho do professor. E assumem a tarefa de ajudar os mais novos em percursos de aprendizagem. Orlando, de certa forma, aprende com eles a ser professor. Para usar uma expressão bastante utilizada nos meios educacionais e copiada de uma frase de Guimarães Rosa, na relação com seus alunos, Orlando é "um professor que de repente aprende". 
Em Memórias de um Professor de Antigamente evidencia-se que as condições materiais e de organização da escola sugerem determinados caminhos de aprendizagem para docentes e alunos. A presença de estudantes de diferentes níveis e idades no mesmo espaço oportuniza, naturalmente, cooperação. Além disso, grupos nos quais há meninos e meninas de diferentes idades possibilitam uma convivência de forma assemelhada àquela que acontece na família e nos ambientes fora da escola. Nas escolas urbanas que conhecemos, o artificialismo da separação em séries contraria modos de convivência das pessoas em sociedade.

Orlando formou-se em curso que propunha uma pedagogia avançada, que privilegiava ensino centrado no aluno e propostas de aprendizagem que aproximassem o ensino da realidade dos estudantes. Mas ele reconhece que não conseguiu concretizar tais direções em seu trabalho no Vale do Ribeira. Registra que "os conteúdos programáticos, naquela época, eram rígidos e minuciosamente definidos por matéria..." (NASCIMENTO, 2020, p. 53). Aponta que a tarefa de planejamento de ensino era facilitada pelo uso do famoso Caderno da Débora, um guia didático que esmiuçava os conteúdos do que deveria ser ensinado. A abordagem era conteudista, mas muito facilitava o trabalho docente. Ao comentar as atividades de planejamento que desenvolvia, o autor observa:

... a imensa maioria dos semanários e diários da época [...] era baseada nos Cadernos da Débora. Confesso que não questionava - como hoje o faço - essa forma de planejar e desenvolver o trabalho; ao contrário, tinha orgulho da competência que exercia em treinar os alunos para 'digerir' os conteúdos e realizar as provas e exercícios propostos, assim como me orgulhei, no final do ano, do alto grau de aprovação dos alunos à série seguinte (NASCIMENTO, 2020, p. 54).

As observações do Orlando sobre metodologia e planejamento de ensino coincidem com as de Zimmerman. Predominava nas escolas de roça o ensino tradicional. Essa constatação precisa ser avaliada com cuidado. O trabalho simultâneo com alunos de diferentes níveis exigia, mesmo quando o ensino era tradicional, estratégias criativas por parte do professor.

O ensino em escolas rurais não atraía docentes formados nas melhores escolas. Por causa do déficit de professores formalmente qualificados para o magistério, era muito comum a existência de professores leigos (muitos deles haviam concluído apenas o curso primário) nas escolas de salas de roça. Zimmerman informa que, na metade do século passado, $60 \%$ dos professores de escolas rurais nos Estados Unidos não eram formados. Enquanto isso, Orlando conta histórias sobre sua experiência em uma única escola, ou seja, seu livro não contém dados estatísticos sobre o magistério na área rural no Brasil. Mas ele faz observações interessantes sobre a existência de "professores leigos". Comenta que, nas reuniões pedagógicas, havia conflitos latentes entre eles o os normalistas. Ao recorrer à sua memória para examinar tais conflitos, o autor expressa grande admiração pelos professores leigos. 
Eles, muitas vezes, poderiam ensinar os professores formados a conduzir o trabaIho docente nas escolas de roça. Reuniam uma experiência que os profissionais com formação acadêmica deveriam considerar. E o autor, professor inexperiente, confessa que recorria a professoras leigas para aprender a lidar com seus alunos.

Memórias de um Professor de Antigamente não é um livro acadêmico. É, como disse, uma coleção de deliciosas crônicas de quem viveu a experiência de ser professor de uma escola de roça. O livro também não é uma obra de história, embora registre lembranças que devem ser consideradas em estudos sobre história da educação no Brasil. É preciso observar ainda que as memórias do professor Orlando devem ter muito de reinterpretação de suas lembranças pessoais com base em estudos superiores que ele fez posteriormente na Faculdade de Educação da Universidade de São Paulo. A formação superior dele na USP certamente filtra as narrativas sobre sua experiência pessoal. Por outro lado, a obra é uma preciosa fonte de informação sobre uma educação pouco conhecida pelos educadores. Seria muito bom que outros professores com experiências similares também registrassem o que viveram em escolas de roça.

\section{Lição a aprender}

Retorno à lição sobre metodologia e didática que as escolas de roça nos podem ensinar. Zimmerman e Orlando veem nas escolas rurais predomínio de um ensino tradicional, voltado para a memorização. Essa é uma interpretação honesta dos autores. Mas essa interpretação me parece muito rigorosa. Nas escolas de roça não se praticava uma educação tradicionalista como a que predominou e talvez ainda predomine nas escolas urbanas. Embora limites de recursos obrigassem as escolas rurais a funcionarem em classe única para alunos de vários níveis e idades, acontecia naquele espaço uma situação que não vemos no ensino rigidamente seriado. Na leitura de ambas as obras, podemos perceber o potencial que uma escola de sala única pode representar em termos de uma educação na qual a cooperação seja o caminho mais comum em aventuras de aprendizagem. A Little Red Schoolhouse e a escola de uma curva do rio Ribeira podem inspirar educadores a encontrarem melhores caminhos para o ensino e a aprendizagem.

\section{Referências}

BATINI, Federico; MAYO, Peter; SURIAN, Alessio. Lorenzo Milani, the school of Barbiana and the Struggle for social justice. New York: Peter Lang Publishing, 2014.

BOTECO ESCOLA. Imagens de escola rurais. 18 fev. 2020. Disponível em: https:// jarbas.wordpress.com/2020/02/18/imagens-de-escolas-rurais/. Acesso em: 02 abr. 2020. 
NASCIMENTO, Orlando Roberto. Memórias de um professor de antigamente. São Paulo: Editora SENAC, 2020.

ROSE, Mike. Possible lives: the promise of public education in America. New York: Penguin Books, 1995.

ZIMMERMAN, Jonathan. Small wonder: the little red schoolhouse in history and memory. New Haven: Yale University Press, 2009.

\section{Jarbas Novelino Barato}

Professor. Doutor em Educação pela Universidade Estadual de Campinas (Unicamp). Mestre em Tecnologia Educacional pela San Diego State University (SDSU). E-mail: jarbas.barato@gmail.com 